\begin{tabular}{|c|c|c|c|c|c|c|}
\hline \multirow{4}{*}{ Impact Factor: } & ISRA (India) & $=4.971$ & SIS (USA) & $=0.912$ & ICV (Poland) & $=6.630$ \\
\hline & ISI (Dubai, UAE & $=0.829$ & РИНЦ (Russia & $=0.126$ & PIF (India) & $=1.940$ \\
\hline & GIF (Australia) & $=0.564$ & ESJI (KZ) & $=8.716$ & IBI (India) & $=4.260$ \\
\hline & JIF & $=1.500$ & SJIF (Morocec & $=5.667$ & OAJI (USA) & $=0.350$ \\
\hline
\end{tabular}

\section{SOI: $1.1 /$ TAS DOI: $10.15863 /$ TAS \\ International Scientific Journal Theoretical \& Applied Science}

p-ISSN: 2308-4944 (print)

e-ISSN: 2409-0085 (online)

Year: 2020

Issue: 03

Volume: 83

Published: 30.03 .2020

http://T-Science.org
QR - Issue

QR - Article
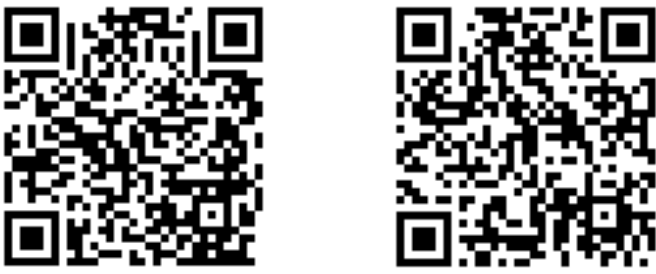

Sultanbek Mukhidovich Toylibayev Nukus State Pedagogical Institute named after Azhiniyaz doctoral candidate, Uzbekistan, Nukus

\title{
MAIN GYMNASTICS - AS ONE OF THE MEANS TO INCREASE PROFESSIONAL ACTIVITY OF STUDENTS OF FACULTIES OF PHYSICAL EDUCATION
}

\begin{abstract}
The article refers to vocational pedagogical training of students of faculties of physical education by means of basic gymnastics, their theoretical knowledge, practical skills, effective use of skills in the chosen discipline, which in turn are refined during the course of state pedagogical practice. The fact that the development and improvement of special professional qualities, knowledge and practical skills of students is carried out precisely during the course of pedagogical practice at the general education school deserves special attention.

The work also deals with the formation of the personality of the teacher, about the further not simple career of the teacher; What is necessary for this, etc. Various methods of using means of main gymnastics in different situations depending on the type of occupations, during lesson, during circle or sectional activity, during carrying out before training gymnastics or carrying out sports minutes, physics pauses, morning aerobics, etc.

The article refers to the beneficial impact on the body engaged in exercises of the main gymnastics, in this regard during the preparation of the work plan of the year cycle (on the example of extracurricular forms of classes) with the help of the means of the main gymnastics will be useful and effective from an educational and health-improving point of view.
\end{abstract}

This article will be useful both for the student and for the teacher of sports specialization.

Key words: preparation, specialist, physical education, main gymnastics, activity.

Language: Russian

Citation: Toylibayev, S. M. (2020). Main gymnastics - as one of the means to increase professional activity of students of faculties of physical education. ISJ Theoretical \& Applied Science, 03 (83), 217-221.

Soi: http://s-o-i.org/1.1/TAS-03-83-42 Doi: crossef https://dx.doi.org/10.15863/TAS.2020.03.83.42

Scopus ASCC: 1201.

\section{ОСНОВНАЯ ГИМНАСТИКА - КАК ОДНО ИЗ СРЕДСТВ ПОВЫШЕНИЯ ПРОФЕССИОНАЛЬНОЙ ДЕЯТЕЛЬНОСТИ СТУДЕНТОВ ФАКУЛЬТЕТОВ ФИЗИЧЕСКОГО ВОСПИТАНИЯ}

Аннотация: В статье говорится о профессиональной педагогической подготовке студентов факультетов физического воспитания по средствам основной гимнастики, об их теоретических знаниях, практических навыках, об эффективном использовании умений по выбранной дисциилине, которые в свою очередь оттачиваются во время прохождения государственной педагогической практики. Отдельного внимания заслуживает и тот факт, что развитие и совершенствование специальных профессиональных качеств, знаний и практических навыков студентов осуществляется именно во время прохождения педагогической практики в общеобразовательной школе.

Также в работе рассматриваются вопросы становления личности педагогика, о дальнейшей не простой карьере педагога; что для этого необходимо и пр. Предложены различные методы использования средств основной гимнастики в различных ситуациях в зависимости от вида занятий, во время урока, во время кружковой или секционной деятельности, во время проведения до учебной гимнастики или проведения спорт минут, физкульт пауз, утренней аэробики и т.д. 


\begin{tabular}{|c|c|c|c|c|c|c|}
\hline \multirow{4}{*}{ Impact Factor: } & ISRA (India) & $=4.971$ & SIS (USA) & $=0.912$ & ICV (Poland) & $=6.630$ \\
\hline & ISI (Dubai, UAE & $=0.829$ & РИНЦ (Russia & $=0.126$ & PIF (India) & $=1.940$ \\
\hline & GIF (Australia) & $=0.564$ & ESJI (KZ) & $=8.716$ & IBI (India) & $=4.260$ \\
\hline & JIF & $=1.500$ & SJIF (Morocec & $=5.667$ & OAJI (USA) & $=0.350$ \\
\hline
\end{tabular}

В статье говорится о благотворном влиянии на организм занимаюшихся упражнений основной гимнастики, в связи с этим во время составление плана работ годичного иикла (на примере внеклассных форм занятий) при помощзи средств основной гимнастики будет полезным и эффективным с образовательной и оздоровительной точки зрения.

Данная статья будет полезной как для студента, так и для учителя физкультурной специиалиации.

Ключевые слова: подготовка, специалист, физическое воспитание, основная гимнастика, деятельность.

\section{Введение}

\section{УДК: 796.011.3}

Профессиональная деятельность студентов факультетов физического воспитания, в том числе их знания, умения и навыки полученные за годы учёбы трансформируются в педагогическую профессию по окончании учебных семестров по выбранной специализации. Очевидно, что целью подготовки кадров является воспитание высококвалифицированных специалистов. Подготовка квалифицированных кадров по физической культуре и спорту отвечающих требованиям современного конкурентного мира основывается на детальном изучении проблематики высшего специального образования.

Актуальность. Сегодняшний студент - это будущий учитель, тренер, наставник. К нашему сожалению, обнаружилось, что вся подготовка студентов к профессиональной деятельности не следует единой концепции, не имеет стратегии, перспективы.

Также нужно отметить и то, что за первые годы самостоятельной педагогической деятельности после окончания ВУЗ-а молодому специалисту явно не достаточно умения и таланта правильного воздействия на занимающихся учеников. Данную ситуацию можно преобразовать путём ввода в образовательную деятельность студентов разделённого подхода формирования занятий, разделяя суть учебного материала по их видам, на примере основной гимнастики. Упражнениями основной гимнастики как одно из основных средств повышения профессионализма или профессиональной деятельности студентов факультетов физического воспитания решаются такие весомые задачи, а именно - формирование правильных двигательных навыков за счёт безмерного комплекса применяемых упражнений. Всем известно, что большую часть физического воспитания занимают практические действия или двигательные умения, навыки и знания.

Исходя из выше сказанного, предлагается следующая интеграция основной гимнастики или перечень гимнастических упражнений (строевые упражнения, обще развивающие упражнения, маховые упражнения, упоры, упражнения в висах и т.д.), которые позволят будущему специалисту физической культуры без особого труда вести свою педагогическую деятельность на высоком, профессиональном уровне в том или ином образовательном учреждении.

Дополнением для

дерей отметить необходимость организовывать образовательную деятельность (упражнениями основной гимнастики) студентов путём внедрения современных технологии, интерактивных методов направленных на формирование у будущих специалистов на инновационно-ориентированное мышление отвечающих современным требованиям сегодняшнего дня, таких как узкоспециализированная секционная (кружковая) работа; поэтапная теоретическая подготовка тренировки по избранному виду спорта (на пример спортивной гимнастики); оздоровительная и ритмическая гимнастика, аэробика, группа - ОФП, и т.д.

Будущему специалисту необходимо суметь хорошо и правильно представить перед собой образ системы подготовки физическим упражнениям во время занятий, так сказать ощутить своё видение текущей проблемы, а именно суметь объяснить своим подопечным ученикам из чего состоит та самая система подготовки физическим упражнениям, главное, как и за счёт чего она осуществляется. В самом начале своей педагогической деятельности молодой специалист путём устного (теоретического) объяснения должен суметь кратко, но понятно «преподнести» своим ученикам ту последовательность использования специальных и общих физических упражнений, правильность распределения их в одном уроке, при этом нормируя необходимую дозировку нагрузок в сочетании пользы для растущего организма ученика $[9,2,1]$.

Следовательно, сложившуюся ситуацию можно расценивать следующим образом: профессиональная педагогическая подготовка сегодняшних студентов помимо теоретических (лекционных, семинарских, курсовых и т.д.работ) занятии в ВУЗ-е также осуществляется во время прохождения студентом государственной педагогической практики. Значит нужно разобраться, в чем заключается суть прохождения студентом государственной педагогической практики в высшем учебном заведении?

Известно, что государственная педагогическая практика студентов высших 


\begin{tabular}{|c|c|c|c|c|c|c|}
\hline \multirow{4}{*}{ Impact Factor: } & ISRA (India) & $=4.971$ & SIS (USA) & $=0.912$ & ICV (Poland) & $=6.630$ \\
\hline & ISI (Dubai, UAE & $=0.829$ & РИНЦ (Russia & $=0.126$ & PIF (India) & $=1.940$ \\
\hline & GIF (Australia) & $=0.564$ & ESJI (KZ) & $=8.716$ & IBI (India) & $=4.260$ \\
\hline & JIF & $=1.500$ & SJIF (Morocec & $=5.667$ & OAJI (USA) & $=0.350$ \\
\hline
\end{tabular}

учебных заведений осуществляется на составленном ранее договоре между высшим учебным заведением и государственным или акционерным, учебным или образовательным, частным, а также совместным предприятиями и прочими дающим знания учреждениями. Для лучшего понимания и усвоения всех тонкостей ведения и преподавания предмета физической культуры нынешним студентом, будет целесообразным прохождение всего периода педагогической практики в общеобразовательной школе. В свою очередь для подробного изучения сути рассматриваемой проблемы следует выделить основной раздел педагогической практики в общеобразовательной школе, а именно овладение студентом методики контроля за физическим развитием и двигательной подготовленностью учащихся. Вообще педагогическая практика является одним из важнейших разделов специальной профессиональной подготовки студентов. Из выше сказанного следует, что основной направленностью преподавания предмета физической культуры в общеобразовательной школе является - обеспечение общего физического образования в единстве с всесторонним воспитанием физических способностей, в конкретном данном случае за счёт упражнений основной гимнастики, укреплением здоровья, совершенствованием свойств телосложения учащихся, воспитанием физических качеств [9]. Также нужно добавить, что современные проблемы развития общества в целом не стоят на месте, и также болезнетворно влияют на развитие детей и учащихся в целом. Углубляться по этим проблемам, которых бесчисленное множество нет никакого смысла.

Следуя по цепочке изучения данной проблематики следует отметить, что в основе программ «Ознакомительной практики» и «Педагогической практики в общеобразовательной школе» выявились их методологическая необоснованность содержания будущему специалисту $[5,4,11]$. Также анализу были подвергнуты все доступные методические нормативные документы, предложения кафедр по совершенствованию практики студентов, отчеты методистов и руководителей практики, и прочая специальная литература по подготовке специалистов по физической культуре и спорту. Как было сказано ранее вся подготовка студентов к профессиональной деятельности не следует единой концепции, не имеет стратегии, перспективы.

В связи с этим возникла необходимость пересмотра сквозной программы учебной и производственной практики студентов факультетов физического воспитания. Образовательным стандартом, а также

программой педагогической практики в общеобразовательных школах

предусматривается выполнение студентомпрактикантом большого объёма учебновоспитательных и тренировочных работ. Нужно отметить и то, что во время прохождения педагогической практики осуществляется проверка и закрепление теоретических знаний и практических навыков (в том числе и по основной гимнастике) студентов в проведении учебной, спортивно-массовой и воспитательной работы с детьми школьного возраста.

Для определения уровня подготовки специалистов физического воспитания, дополнительно были подвергнуты изучению доступные материалы по прохождению государственной педагогической практике в Нукусском государственном педагогическом институте и Каракалпакском государственном университете. Нами были рассмотрены планы работ кафедр, перспективный план по реализации государственной педагогической практики, методические разработки, государственный образовательный стандарт, общие положения высших учебных заведений подготовки специалистов физического воспитания.

По результатам вышеуказанных факторов сформировалась противоречие, с одной стороны это бесперебойное развитие и углубление качества специальной профессиональной подготовки студентов, а с другой стороны это критический низкий уровень инновационной, научной и методической изученности вопросов профессиональной подготовки, умении, навыков и знаний. В этой связи выполнение данного исследования по указанной ранее проблематики является обоснованным и целесообразным.

Объектом исследования является повышение профессиональной подготовленности студентов факультетов физического воспитания.

Предмет

совершенствование профессионального мастерства по средствам основной гимнастики (умений, навыков и знаний) студентов факультетов физического воспитания.

Цель исследования - повышение профессионализма, профессиональной подготовки студентов по специализации физической культуры и спорта, путём насыщения и улучшения методики обучения и программы образовательного процесса по «гимнастическим» дисциплинам.

Методы исследования. В решении поставленных задач использовался метод теоретического анализа и обобщенные данные научно-методической литературы.

Для решения вышеуказанной задачи, в первую очередь необходимо разобраться, что такое основная гимнастика и какова её роль в 


\begin{tabular}{|c|c|c|c|c|c|c|}
\hline \multirow{4}{*}{ Impact Factor: } & ISRA (India) & $=4.971$ & SIS (USA) & $=0.912$ & ICV (Poland) & $=6.630$ \\
\hline & ISI (Dubai, UAE & $=0.829$ & РИНЦ (Russia & $=0.126$ & PIF (India) & $=1.940$ \\
\hline & GIF (Australia) & $=0.564$ & ESJI (KZ) & $=8.716$ & IBI (India) & $=4.260$ \\
\hline & JIF & $=1.500$ & SJIF (Morocce & $=5.667$ & OAJI (USA) & $=0.350$ \\
\hline
\end{tabular}

профессиональной подготовке высококлассных специалистов физической культуры. Основная гимнастика - это особая система упражнений и средств гигиены, используемых для общего всестороннего физического развития и оздоровления, а в данном случае у учащихся студентов факультетов физического воспитания, укрепления и улучшения их здоровья, гармоничного развития всех органов и систем, а также развития таких качеств как сила, быстрота, гибкость, ловкость и выносливость $[12,8,13,15]$.

Применяя те или иные элементы упражнении основной гимнастики, особое внимание следует обращать на всестороннее воздействие их на организм в целом, а также на физическую нагрузку, которая строго дозируется в зависимости от индивидуальных особенностей занимающихся. По курсу физиологии известно что, с возрастом организм становится менее податливее, таким гимнастическим воздействиям как растягивания, в связи с этим эластика связок также теряет былое совершенство. Все это выражается в уменьшении предельно возможной амплитуды движений. С педагогической точки зрения, для повышения зрелищности и активизации интереса, а также для вовлечения большего количества одновременно занимающихся (школьников, студентов, спортсменов и т.д.) применяются игровой, поточный и групповой способы проведения занятии.

Были изучены и проанализированы исследования передового опыта ведущих специалистов, такие как критерии мастерства специалиста физического воспитания, особенности специальной подготовленности, значение и последовательность «Гимнастики», где рассматривался вопрос о профессиональной подготовке педагогических кадров $[9,11,14]$.

Литературные данные показали, что, для лучшего овладения техникой и приёмами выполнения тех или иных упражнений прежде всего нужно мысленно представить и желательно «кадр за кадром» прокрутить в голове как совершается каждое отдельное движение и все движения в совокупности, уметь мысленно воспроизвести их в хронологическом порядке, а иногда и в беспорядочной форме $[5,4,13]$. Перед сумевшим понять этот принцип механического действия студентом стоит его главная задача: а именно в лёгкой и понятной форме донести всё выше сказанное до своих учеников. В начальных этапах педагогической практики, как уже предлагалось ранее в статье «Некоторые особенности профессиональной деятельности

Тойлибаев С.М. - «Некоторые особенности профессиональной деятельности студентов факультетов физической культурыз». Статья ХІ Международной научно- студентов факультетов физической культурыл» ${ }^{1}$ следует уделять особое внимание элементам оздоровительной гимнастики, где студентпрактикант для начала должен уметь донести до учеников правила элементарного построения (строй формируется по росту учащихся, с левой стороны от студента-практиканта где юноши строятся первыми, за ними выстраиваются девочки также по росту). Для учеников начальных классов выполнение комплекса несложных упражнений для общего понятия о физкультуре в целом (например: исходное положение: «ноги ставятся на ширине плеч, руки на пояс, вращение головы в стороны по 3-4 раза и т.д.) с определённой последовательностью выполнении (сверху вниз или наоборот), далее следует выполнение комплексов растягиваний с несколькими повторениями и т.д.

Для учеников средних классов рекомендуется изучение поворотов на месте и в движение с подробным теоретическим объяснениями и наглядными примерами практиканта (выполнение поворота кругом на пятке левой ноги и на носке правой ноги в сторону левого плеча на $180^{\circ}$ и др.) А для учеников старших классов предусматривается выполнение более сложных элементов спортивной гимнастики, такие как чередование упражнений в висах и упорах $[3,5,6]$.

Продолжая тему подготовки специалиста физического воспитания сегодняшним студентам необходимо быть внимательными к деятельности «более опытных» педагогов и тренеров. Важно помнить и то, что полностью копировать ту или иную «технику» того или иного специалиста бессмысленно и даже опасно, т.е. следует ничего перенимать безумно, это бессмысленно. Что хорошо одному, не всегда подходит другому. Для студента будет правильным продумать, хорошенько проанализировать, попробовать испытать на своей практике и потом взять на вооружение методику (последовательность, оригинальность, целостность, часть и т.д.) по ведению занятия, кружковой и внеклассной форм занятий по средствам основной гимнастики $[7,3$, $2]$.

Подготовка студентов по средствам основной гимнастики, следует отметить и то, что гимнастика благотворно влияет на организм человека, особенно на организм юного возраста. Двигательный аппарат (кости, их сочленение, мышцы) работают в организме не каждый сам по себе, не изолировано, а во взаимодействии с другими органами и системами. Работа двигательного аппарата контролируется и 


\begin{tabular}{|c|c|c|c|c|c|c|}
\hline \multirow{4}{*}{ Impact Factor: } & ISRA (India) & $=4.971$ & SIS (USA) & $=0.912$ & ICV (Poland) & $=6.630$ \\
\hline & ISI (Dubai, UAE & $=0.829$ & РИНЦ (Russia & $=0.126$ & PIF (India) & $=1.940$ \\
\hline & GIF (Australia) & $=0.564$ & ESJI (KZ) & $=8.716$ & IBI (India) & $=4.260$ \\
\hline & JIF & $=1.500$ & SJIF (Morocec & $=5.667$ & OAJI (USA) & $=0.350$ \\
\hline
\end{tabular}

регулируется центральной нервной системой мозгом человека. В свою очередь двигательный аппарат влияет на деятельность центральной нервной системы, следовательно, и на деятельность организма в целом. Разнообразные последовательные движения (в нашем случае упражнения), работа мышц возбуждают нервную систему, тем самым активизируется деятельность коры головного мозга. В движении увеличивается приток крови по всему двигательному аппарату, усиливается дыхание. Таким образом, гимнастика даёт возможность регулировать работу всего организма, укрепляет его, «тонизирует» и организует его правильную деятельность.

Правильно подобранные специалистом физической культуры, а в нашем случае студентом-практикантом гимнастические упражнения позволяют разносторонне воздействовать на те, или иные группы мышц, на внутренние органы, а также дыхательную систему и на общее бодрое самочувствие учащегося в целом. Отдельно нужно отметить и то, что полезные свойства гимнастики не заканчиваются выше сказанным, улучшается осанка, появляется плавность, равномерность движений, наблюдается эластичность в движениях, тело становится стройным, кожа приобретает более свежий вид, что не мало важно при сегодняшней экологической загрязненности, появляется румянец. Соответственно изменяется и психика ребёнка, появляется радостное ощущение здоровья, бодрости, прилив энергии $[3,1]$.

Доказано, что гимнастика является одним из действенных средств борьбы с преждевременным старением (Ф.Л.Доленко, Р.А.Белов, Б.В.Сермеев и др.). Гимнастические упражнения не только улучшают деятельность сердца и легких, но и благотворно влияют на весь обмен веществ. К большому сожалению, гибкость (в том числе и осанка) в отличие от других физических качеств начинает регрессировать в силу возрастных изменений уже с первых лет жизни человека $[9,1$, 10].

Дополнительным методическим указанием правильно будет отметить, что при занятиях гимнастикой и составления плана занятий очень важно правильно подобрать упражнения, их количество, последовательность, дозировку во времени. Есть одно золотое правило, что каждый выполняемый комплекс гимнастических упражнений должен выстраиваться по принципу от простого к сложному, от лёгкого к более трудному упражнению. Каждое упражнение содержит в себе два основных момента: правильное исходное (начальное) положение и правильно выполненное движение.

Выводы. Из-за неудовлетворительной научно-практической обоснованности процесса становления специалиста физического воспитания, а именно из-за малоэффективных показателей профессиональных умений, навыков и знаний по специализации привело к тому, что молодой специалист не может или затрудняется в самореализации первые годы своей педагогической карьеры. Это положение исправимо, для этого следует пересмотреть содержательную и организационную стороны программ образовательного стандарта, путём объективного (оптимального) выбора средств основной гимнастики в профессиональной подготовке студентов факультетов физического воспитания.

\section{References:}

1. Babushkin, G.D. (1987). Struktura professional'nogo interesa i sklonnost' $\mathrm{k}$ pedagogicheskoj dejatel'nosti. Voprosy psihologii, №2.

2. (1973). Voprosy fizicheskogo vospitanija studentov VIII. Izdatel'stvo Leningradskogo universiteta.

3. Ivanov, I.S. (1952). 250 gimnasticheskih uprazhnenij. (pp.6-19). Moscow.

4. Maslov, B.B. (1989). Podgotovka specialistov po fizicheskoj kul'ture $i$ sportu $v$ institutah fizicheskoj kul'tury. Moscow.

5. Matveev, L.P. (1998). Formy postroenija zanjatij $v$ fizicheskom vospitanii. Moscow.

6. Mihajlova, T.V. (2009). Social'nopedagogicheskie osnovy dejatel'nosti trenera. Moscow: Fizicheskaja kul'tura.

7. Polievskij, S.A., \& Starceva, I.D. (1988). Fizkul'tura i professija. Moscow: FiS.
8. (1969). Sportivnaja gimnastika. Pod obshhej redakciej V.P.Frolova (Ed.). Moscow: Vysshaja shkola.

9. (1976). Teorija $i$ metodika fizicheskogo vospitanija. T. 2. Moscow: Fizkul'tura i sport.

10. (1987). Fizicheskoe vospitanie v shkole 4-10-h klassov. T.S.Umanhodzhaev, S.G.Arzumanov, G.M.Sergeev i dr. (Ed.). Tashkent: Medicina.

11. Hotenko, E.P., Zaripova, G.M., \& Mustafaev, Sh.A. (1989). Pedraktika v shkole. Nukus.

12. (1962). Jenciklopedicheskij slovar' po fizicheskoj kul'ture i sportu. T. 2. Moscow: Fizkul'tura i sport.

13. Junusova, Ju.M. (2005). Osnovy metodiki fizicheskoj kul'tury. Tashkent.

14. (n.d.). Retrieved from www.sportedu.uz

15. (n.d.). Retrieved from www.gov.uz

16. (n.d.). Retrieved from www.gymnastics.uz 